\title{
A procedure for calculating a consistent set of closure temperatures and cooling rate using Dodson's formula
}

\section{Jinichiro Maeda*, Ryoichi Zeniya*, Yoshiyuki Kuramoto*, Tetsumaru Itaya** and Hiroo Kagami*}

Received June 2, 2010

Accepted October 29, 2010

Department of Natural History Sciences, Faculty of Science, Hokkaido University, N10 W8, Kita, Sapporo, Hokkaido 060-0810, Japan

** Research Institute of Natural Sciences, Okayama University of Science, 1-1 Ridai-cho, Kita-ku, Okayama, Okayama 700-0005, Japan

**** 2053-16, Ōmachi, Ōmachi, Nagano 398-0002, Japan

Corresponding author; J. Maeda,

jinmaeda@mail.sci.hokudai.ac.jp

\begin{abstract}
The cooling rate of a geological material is generally calculated using two isotopic ages with different closure temperatures; however, the closure temperature is itself dependent on the cooling rate. Here we present a simple procedure for calculating a consistent set of closure temperatures and cooling rate using Dodson's mathematical formula.
\end{abstract}

Keywords: closure temperatures, cooling rates, Dodson's formulation, Tanzawa plutonic complex, Atlantis Bank, ODP Hole 735B

\section{Introduction}

Closure temperature can be defined as the temperature of the system at the time corresponding to its apparent age (Dodson, 1973). On this basis, it is possible to calculate the cooling rates of the system using closure temperatures of a variety of minerals combined with their isotopic ages (e.g., Harrison et al., 1979). In such calculations, we often use closure temperatures shown by Dodson and McClelland-Brown (1985), who gave $510^{\circ} \mathrm{C}$ for hornblende and $300^{\circ} \mathrm{C}$ for biotite in $\mathrm{K}-\mathrm{Ar}$ system on cooling rate of $30^{\circ} \mathrm{C} / \mathrm{myr}$ (myr=million years), for example. However, closure temperature is itself dependent on cooling rate, as shown in the analytical model of Dodson (1973). Here we present a simple and convenient procedure for calculating a consistent set of closure temperatures and cooling rates using two isotopic ages with different closure temperatures.

\section{Procedure of calculation}

Dodson (1973) gave the following equation for calcu- lating closure temperatures:

$$
E / R T_{c}=\ln \left[-A D_{0} R T_{\mathrm{c}}^{2} /\left\{a^{2}(d T / d t) E\right\}\right],
$$

where $E$ is the activation energy for the diffusion process, $R$ is the gas constant, $T_{C}$ is the closure temperature, $A$ is the numerical constant depending on geometry, $D_{0}$ is the diffusion coefficient at infinitely high temperature, $d T / d t$ is the cooling rate ( $d T$ and $d t$ are the differences in temperature and time, respectively: $d T=T_{\text {present }}-T_{C}<0$ and $d t=t_{\text {presen }}-t_{C}\left(t_{C}=0\right)>0$, so $d T / d t$ is negative for cooling) and $a$ is an effective diffusion dimension (i.e., radius in the case of a sphere). Since $T_{C}$ appears on both sides of equation (1), this equation must be solved iteratively for a given value of cooling rate. Sufficient convergence would be obtained by several iterations.

If it is assumed that $d T / d t$ was constant for an interval between $T_{C}$ of two different ages, a consistent set of $T_{C}$ and $d T / d t$ can be obtained. First, a trial value of cooling rate is given by difference in roughly assumed $T_{C}$ for two different ages, A and B (Fig. 1). Convergence of $T_{C}$ would be obtained by several iterations of equation (1) for each of A and B (N2 and N3 iterations in Fig. 1, respectively). Using the cooling rate obtained from the converged $T_{C}$ of $\mathrm{A}$ and $\mathrm{B}$, more precise values of $T_{C}$ of A and B would be obtained by the next iteration of $\mathrm{N} 1$. After several iterations of $\mathrm{N} 1$, consistent values of $T_{C}$ of $\mathrm{A}$ and $\mathrm{B}$ and cooling rate would be obtained. One of two $T_{C}$ can be held constant by omitting either iteration N2 or N3. A Microsoft Excel spreadsheet for calculating $T_{C}$ and $d T / d t$ may be available from http://www.sci. hokudai.ac.jp/ jinmaeda/ or from JM on request (jinmaeda@mail.sci.hokudai.ac.jp).

\section{Applications}

The procedure presented above may be particularly useful for rapidly cooled plutonic and metamorphic rocks. We applied the calculation procedure to two plutonic suites, gabbroic lower crust exposed at Atlantis Bank on the Southwest Indian Ridge and Tanzawa granitic pluton in central Japan.

1. Lower oceanic crust exposed at Atlantis Bank on the Southwest Indian Ridge

Atlantis Bank is a wave-cut terrace at a water depth of $\sim 700 \mathrm{~m}$ along an eastern transverse ridge of the Atlantis II Fracture Zone, $57^{\circ} \mathrm{E}$ on the ultraslow-spreading 


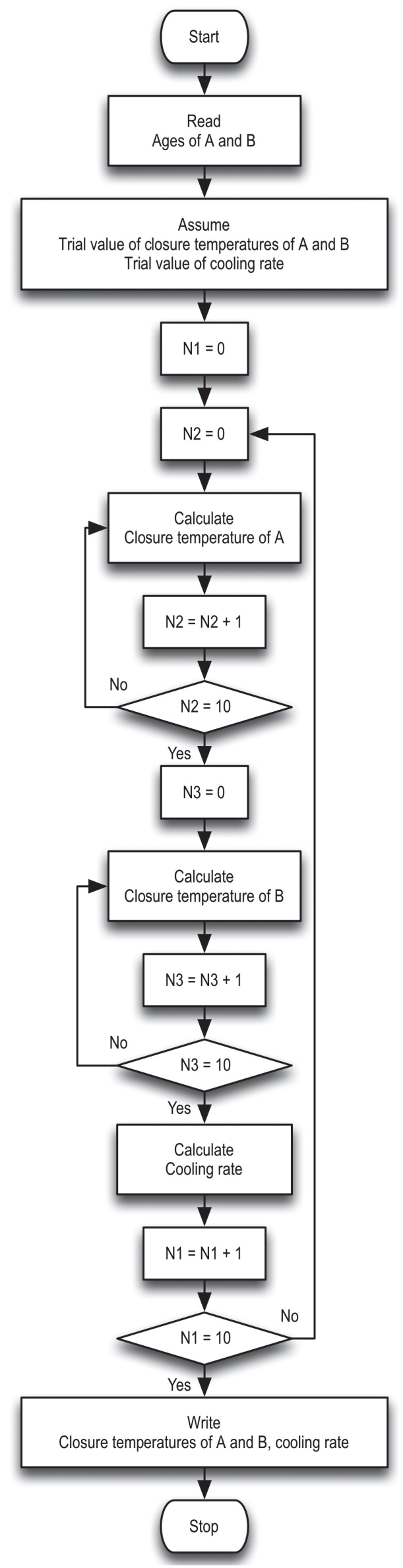

Southwest Indian Ridge (e.g., Dick et al., 1999). Detailed observations and samplings conducted by drilling (ODP Holes 735B and 1105A), dredging, manned submersible and ROV revealed that Atlantis Bank is a typical oceanic core complex, that is an uplifted block of lower oceanic crust and upper mantle by detachment faulting (e.g., Dick et al., 2000; John et al., 2004; Baines et al., 2008). John et al. (2004) estimated a cooling rate of $1600{ }^{\circ} \mathrm{C} / \mathrm{myr}$ for temperatures between $850{ }^{\circ} \mathrm{C}$ and $350^{\circ} \mathrm{C}$ by thermochronological approach on the Hole 735B rocks. Coogan et al. (2007) determined a cooling rate of the order of $10^{3}-10^{4} \mathrm{C} / \mathrm{myr}$ of the Hole $735 \mathrm{~B}$ gabbros between $1000{ }^{\circ} \mathrm{C}$ and $600{ }^{\circ} \mathrm{C}$ using Ca-in-olivine geospeedmeter. Most recently, Schwartz et al. (2009) showed a cooling rate of $1200^{\circ} \mathrm{C} / \mathrm{myr}$ based on U-Pb and $(\mathrm{U}-\mathrm{Th}) / \mathrm{He}$ ages of zircon with assumed $T_{C}$ of $850^{\circ} \mathrm{C}$ and $200{ }^{\circ} \mathrm{C}$, respectively, and discussed that the core complex cooled rapidly during detachment faulting. We calculated internally consistent sets of $T_{C}$ and cooling rates for three samples shown by Schwartz et al. (2009). Diffusion parameters of $\mathrm{Pb}$ in zircon are from Lee et al. (1997) and Cherniak and Watson (2000) and those of $\mathrm{He}$ is from Reiners et al. (2004) (Table 1). Effective grain radii of zircons are assumed to be $50 \mu \mathrm{m}$ after Schwartz et al. (2009). Our calculation (Table 2) yields higher $T_{C}$ of both $\mathrm{U}-\mathrm{Pb}$ and (U-Th)/He ages than those assumed by Schwartz et al. (2009). This means that their $T_{C}$ are too low to match the proposed cooling rate. As shown in Table 2, $T_{C}$ of $\mathrm{U}-\mathrm{Pb}$ ages calculated using parameters of Cherniak and Watson (2000) are $~ 70-90^{\circ} \mathrm{C}$ higher than those using parameters of Lee et al. (1997). However, these $T_{C}$ and cooling rates are consistent within uncertainties.

\section{Tanzawa plutonic complex in Izu collision zone, central Japan}

The Tanzawa plutonic complex is located in the Izu collision zone in central Japan, where the northern tip of

Fig. 1. $(\leftarrow)$ Procedure for calculating a consistent set of closure temperatures and cooling rate. This procedure represents a combination of calculations using equation (1) for two isotopic ages with different closure temperatures (A and B). First, a rough value of the cooling rate $(d T / d t)$ is obtained from the isotopic ages and assumed closure temperatures $\left(T_{C}\right)$ of $\mathrm{A}$ and $\mathrm{B}$. Using the cooling rate and $T_{C}$ as trial values, convergence of $T_{C}$ for $\mathrm{A}$ and $\mathrm{B}$ is obtained by performing 10 iterations of N2 and N3. Because a difference in the converged $T_{C}$ of $\mathrm{A}$ and $\mathrm{B}$ would yield a more precise value of the cooling rate, each additional iteration of $\mathrm{N} 1$ yields more precise $T_{C}$ values for $\mathrm{A}$ and $\mathrm{B}$. After 10 iterations of $\mathrm{N} 1$, we obtain consistent values of $T_{C}$ for $\mathrm{A}$ and $\mathrm{B}$ and the cooling rate. One of the two $T_{C}$ values (of A and B) can be held constant by omitting iteration N2 or N3. 
Table 1. Diffusion parameters of $\mathrm{Pb}$ and $\mathrm{He}$ in zircon. Geometry of zircon is spherical and numerical constant $A$ in equation (1) is 55 (Dodson, 1973).

\begin{tabular}{crrl}
\hline Isotopic system & \multicolumn{1}{c}{$E(\mathrm{cal} / \mathrm{mol})$} & \multicolumn{1}{c}{$D_{0}\left(\mathrm{~cm}^{2} / \mathrm{s}\right)$} & \multicolumn{1}{c}{ References } \\
\hline $\mathrm{U}-\mathrm{Pb}$ & $161,000( \pm 8,000)$ & $3.90 \times 10^{9}\left(+7.76 \times 10^{10} /-3.70 \times 10^{9}\right)$ & Lee et al. (1997) \\
$\mathrm{U}-\mathrm{Pb}$ & $130,000( \pm 6,000)$ & $7.76 \times 10^{2}\left(+5.04 \times 10^{3} /-6.73 \times 10^{2}\right)$ & Cherniak and Watson (2000) \\
$(\mathrm{U}-\mathrm{Th}) / \mathrm{He}$ & $40,400( \pm 900)$ & $4.60 \times 10^{-1}\left(+8.70 \times 10^{-1} /-3.00 \times 10^{-1}\right)$ & Reiners et al. (2004) \\
\hline
\end{tabular}

the Izu-Bonin-Mariana (IBM) arc has been colliding against the Honshu arc from Middle Miocene (e.g., Saito et al., 2007; Yamada and Tagami, 2008). Tani et al. (2010) concluded that the Tanzawa complex was not denuded middle crust of the IBM arc but formed during arc-arc collision. Tani et al. (2010) calculated cooling rates of the Tanzawa pluton using $\mathrm{U}-\mathrm{Pb}$ and $(\mathrm{U}-\mathrm{Th}) / \mathrm{He}$ ages of zircon. They used Ti-in-zircon temperatures instead of $T_{C}$ for $\mathrm{U}-\mathrm{Pb}$ ages, and assumed that $T_{C}$ for (U$\mathrm{Th}) / \mathrm{He}$ ages is $180^{\circ} \mathrm{C}$ according to Yamada and Tagami (2008). Using the procedure presented in this paper, we calculated consistent sets of $T_{C}$ of zircon (U-Th)/He age and cooling rate for two samples. Diffusion parameters of He in zircon are from Reiners et al. (2004). Effective radii of zircons of the dated samples, $60 \mu \mathrm{m}$, are from Yamada and Tagami (2008). Our results shown in Table 2 indicate that slightly higher $T_{C}$ of $(\mathrm{U}-\mathrm{Th}) / \mathrm{He}$ ages and slightly slower cooling compared to those given by Tani et al. (2010). This means that the assumed $T_{C}$ of (U-Th)/ He age, $180^{\circ} \mathrm{C}$, is low and not suitable for the cooling rates. Smaller intervals between Ti-in-zircon temperatures for $\mathrm{U}-\mathrm{Pb}$ age and $T_{C}$ of (U-Th)/He age produced slightly lower cooling rates compared to those given in Tani et al. (2010) as shown in Table 2.

\section{Uncertainties in the results}

Uncertainties in the calculated cooling rates may be mainly stemming from errors in ages and $T_{C}$. We assume that uncertainty in $T_{C}$ could be produced only by experimental errors in diffusion parameters, $E$ and $D_{0}$. Furthermore, we define uncertainty on cooling rate as (maximum cooling rate-minimum cooling rate) $/ 2$, where the maximum cooling rate is maximum $d T /$ minimum $d t$ and the minimum cooling rate is minimum $d T /$ maximum $d t$ (here $d T$ is absolute value of $T_{\text {present }}-T_{C}$ ). Let us consider now two ages $A$ and $B: A \pm a$ with $T_{C}$ of $X \pm x$ and $B \pm b$ with $T_{C}$ of $Y \pm y(A>B, X>Y)$. The lower case letters refer to errors. Minimum and maximum cooling rates are expressed as $\{(X-x)-(Y+y)\} /\{(A+a)-(B-b)\}$ and $\{(X+x)-(Y-y)\} /\{(A-a)-(B+b)\}$, respectively. Since minimum $d t$ may be negative in some case, we redefine uncertainty of cooling rate as nominal cooling rateminimum cooling rate, i.e., $\{(X-Y) /(A-B)\}-\{(X-x)-$ $(Y+y)\} /\{(A+a)-(B-b)\}$. Values of $x$ and $y$ are determined by calculation of $T_{C}$ using combination of maximum and/or minimum values of $E$ and $D_{0}$. Thus, cooling rate is expressed as $(X-Y) /(A-B) \pm[\{(X-Y) /(A-B)\}-\{(X-x)-$ $(Y+y)\} /\{(A+a)-(B-b)\}]$. Experimental errors in the diffusion parameters of $\mathrm{Pb}$ and $\mathrm{He}$ in zircon are given in Table 1. Calculated uncertainties in cooling rates and $T_{C}$ of the Atlantis Bank gabbros and Tanzawa granites are shown in Table 2. Detail of the estimation of uncertainties is given in the Microsoft Excel spreadsheet.

\section{Utility of the proposed procedure}

Using the procedure we proposed here, we calculated internally consistent sets of cooling rates and $T_{C}$ for the abovementioned two suites. However, it is noted that this procedure does not increase the accuracy of the calculations of cooling rate and $T_{C}$. Closure temperatures, $T_{C}$, often used in calculation of cooling rates are those standardized to a cooling rate of $30^{\circ} \mathrm{C} / \mathrm{myr}$ by Dodson and McClelland-Brown (1985). If cooling rate calculated using such $T_{C}$ is of the order of $\geq \sim 10^{2}-10^{3 \circ} \mathrm{C} / \mathrm{myr}$, inconsistency between $T_{C}$ and cooling rate would be serious. The procedure presented in this paper is useful in such cases to determine an internally consistent set of $T_{C}$ and cooling rate.

\section{Acknowledgements}

We thank Toru Yamasaki, Marie Python, Hiroto Ohira and an anonymous reviewer for their constructive comments.

\section{References}

Baines, A. G., Cheadle, M. J., John, B. E. and Schwartz, J. J., 2008, The rate of oceanic detachment faulting at Atlantis Bank, SW Indian Ridge. Earth Planet. Sci. Lett., 273, 105 114.

Cherniak, D. J. and Watson, E. B., 2000, Pb diffusion in zircon. Chem. Geol., 172, 5-24.

Coogan, L. A., Jenkin, G. R. T. and Wilson, R. N., 2007, Contrasting cooling rates in the lower oceanic crust at fast- and slow-spreading ridges revealed by geospeedometry. Jour. 


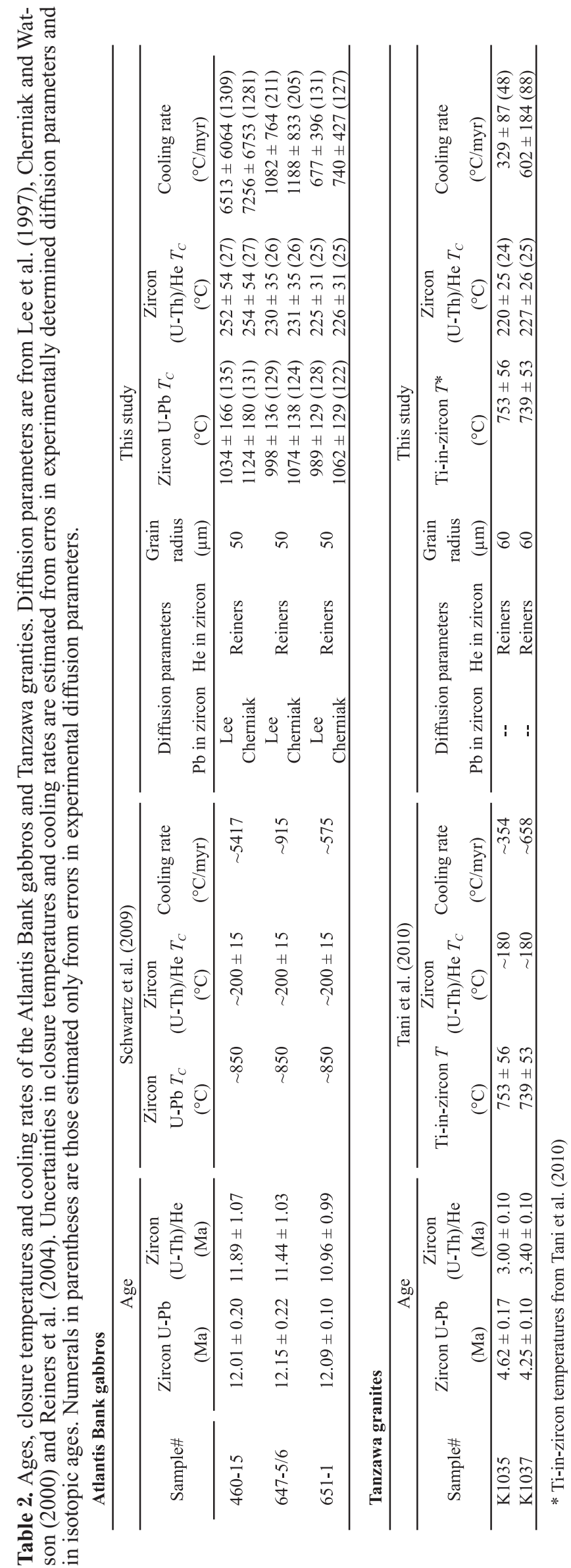


Petrol., 48, 2211-2231.

Dick, H. J. B., Natland, J. H., Miller, D. J. and Scientific Party, 1999, Proceedings of the Ocean Drilling Program, Initial Report Leg 176. Ocean Drill. Prog., College Station, Texas.

Dick, H. J. B., Natland, J. H., Alt, J. C., Bach, W., Bideau, D., Gee, J. S., Haggas, S., Hertogen, J. G. H., Hirth, G., Holm, P. M., Ildefonse, B., Iturrino, G. J., John, B. E., Kelley, D. S., Kikawa, E., Kingdon, A., LeRoux, P. J., Maeda, J., Meyer, P. S., Miller, D. J., Naslund, H. R., Niu, Y.-L., Robinson, P. T., Snow, J., Stephen, R. A., Trimby, P. W., Worm, H.-U. and Yoshinobu, A., 2000, A long in situ section of the lower ocean crust; results of ODP Leg 176 drilling at the Southwest Indian Ridge. Earth Planet. Sci. Lett., 179, 31-51.

Dodson, M. H., 1973, Closure temperature in cooling geochronological and petrological systems. Contrib. Mineral. Petrol., 40, 259-274.

Dodson, M. H. and McClelland-Brown, E., 1985, Isotopic and paleomagnetic evidence for rates of cooling, uplift and erosion. Geol. Soc. Mem., 10, 315-325.

Harrison, T. M., Armstrong, R. L., Naeser, C. W. and Harakal, J. E., 1979, Geochronology and thermal history of the Coast Plutonic Complex, near Prince Rupert, British Columbia. Can. Jour. Earth Sci., 16, 400-410.

John, B. E., Foster, D. A., Murphy, J. M., Cheadle, M. J., Baines, A. G., Fanning, C. M. and Copeland, P., 2004, Determining the cooling history of in situ lower oceanic crust-
Atlantis Bank, SW Indian Ridge. Earth Planet. Sci. Lett., 222, 145-160.

Lee, J. K. W., Williams, I. S. and Ellis, D. J., 1997, Pb, U and Th diffusion in natural zircon. Nature, 390, 159-162.

Reiners, P. W., Spell, T. L., Nicolescu, S. and Zanetti, K. A., 2004, Zircon (U-Th)/He thermochronometry: He diffusion and comparisons with ${ }^{40} \mathrm{Ar} /{ }^{39} \mathrm{Ar}$ dating. Geochim. Cosmochim. Acta, 68, 1857-1887.

Saito, S., Arima, M., Nakajima, T., Misawa, K. and Kimura, J.-I., 2007, Formation of distinct granitic magma batches by partial melting of hybrid lower crust in the Izu arc collision zone, central Japan. Jour. Petrol., 48, 1761-1791.

Schwartz, J. J., John, B. E., Cheadle, M. J., Reiners, P. W. and Baines, A. G., 2009, Cooling history of Atlantis Bank oceanic core complex: Evidence for hydrothermal activity 2.6 Ma off axis. Geochem. Geophys. Geosyst., 10, Q08020 http://dx.doi.org/10.1029/2009GC002466.

Tani, K., Dunkley, D. J., Kimura, J.-I., Wysoczanski, R. J., Yamada, K. and Tatsumi, Y., 2010, Syncollisional rapid granitic magma formation in an arc-arc collision zone: Evidence from the Tanzawa plutonic complex, Japan. Geology, 38, 215-218.

Yamada, K. and Tagami, T., 2008, Postcollisional exhumation history of the Tanzawa tonalite complex, inferred from (U$\mathrm{Th} / \mathrm{He}$ thermochronology and fission track analysis. Jour. Geophys. Res., 113, B03402, doi: 10.1029/2007JB005368. 